\title{
PENGARUH KATALIS BENTONIT PADA HASIL VOLUME SYNGAS GASIFIKASI LIMBAH KAYU GALAM DAN BATUBARA KUALITAS RENDAH
}

\author{
Ahmad Fitrianor ${ }^{1)}$, Aqli Mursadin ${ }^{2)}$ \\ 1,2Program Studi Teknik Mesin \\ Fakultas Teknik Universitas Lambung Mangkurat \\ JL. Akhmad Yani Km. 36 Banjarbaru, Kalimantan Selatan,70714 \\ e-mail: ahmadfitrianorhadiprayugo@gmail.com
}

\begin{abstract}
This study aims to determine and compare the results of the syngas volume generated from variations in mixing of galam wood powder and bentonite catalyst coal. This research was carried out by mixing galam wood powder and coal with a mass of $200 \mathrm{~g}$ which was given a bentonite catalyst. There were 4 variations of mixing ingredients namely $200 \mathrm{~g}$ galam wood powder and $0 \mathrm{~g}$ coal, $180 \mathrm{~g}$ galam wood powder and $20 \mathrm{~g} \mathrm{coal,} 140 \mathrm{~g}$ galam wood powder and $60 \mathrm{~g}$ coal, $100 \mathrm{~g}$ galam wood powder and $100 \mathrm{~g} \mathrm{coal}$ which added $50 \%, 30 \%$ and $10 \%$ bentonite catalysts from the mass of material in each variation of the temperature. Material in updraft gasification with a temperature of $500^{\circ} \mathrm{C}$ for 120 minutes or 2 hours. The results showed that variations with a mixture of $200 \mathrm{~g}$ of galam wood powder and $0 \mathrm{~g} \mathrm{coal}$ were the ones that produced the most syngas. This was due to the density of galam wood powder which was more tenuous so it was more flammable at temperatures up to $500^{\circ} \mathrm{C}$. The amount of bentonite catalyst addition also affects the volume of syngas produced, where the more addition of bentonite catalysts the more syngas volume is produced, this is because bentonite contains $\mathrm{Al}_{2} \mathrm{O}_{3}$ which has good heat conductivity so the heating rate is faster, due to the heating rate faster makes the syngas volume produced more for 120 minutes when gasification.
\end{abstract}

Keywords: Updraft Gasification, Galam Wood Powder, Coal Gasification, Bentonite Catalyst Gasification

\section{PENDAHULUAN}

Gland Steam Condensor (GSC) adalah penukar panas (heat exchanger) untuk mengkondensasikan uap bekas dari perapat poros turbin. Uap bekas ini akan memanaskan air kondensat dari pompa kondensat yang dialirkan melintasi Gland Steam Condensor. Karena panasnya diserap oleh air kondensat, uap bekas dari perapat poros akan mengembun dan selanjutnya dialirkan ke hotwell.

Energi merupakan bagian penting dalam kehidupan manusia karena hampir semua aktivitas di dunia membutuhkan energi, semakin bertambahnya populasi penduduk dunia menyebabkan kebutuhan energi semakin meningkat, khususnya di Indonesia. Oleh sebab itu energi terbarukan sangat di butuhkan untuk membantu memenuhi kebutuhan energi.

Biomassa merupakan Renewable Energy Sources (RES) yang tersedia secara berkelanjutan di alam. Indonesia merupakan penghasil biomassa terbesar di ASEAN akan tetapi pemanfaatanya masih kurang maksimal (Rantanen, 2009). Contoh biomassa antara lain adalah tanaman, pepohonan, rumput, ubi, limbah pertanian, limbah hutan, tinja dan kotoran ternak. Di Indonesia kayu merupakan biomassa yang sudah lama dikenal oleh masyarakat dan merupakan sumber energi terbarukan (Maharjoeno, 2005).

Indonesia mempunyai potensi akan biomassa yang sangat besar salah satunya adalah kayu galam. Kayu galam (Maleleuca $s p$ ) ditemukan melimpah di hutan rawa gambut di pesisir Kalimantan dan Sumatera Selatan. Batang kayu 
galam panjang dan cenderung lurus atau bagus, menyebabkan kayu ini mempunyai nilai pemanfaatan yang penting. Galam memiliki prospek yang bagus untuk dikelola dengan baik dan dikembangkan karena pertumbuhan galam yang begitu pesat yaitu dengan diameter batang 1 sampai $1,5 \mathrm{~cm} /$ tahun (Rachmanady dkk, 2004). Limbah bekas pemotongan kayu galam yang berupa serbuk sangat melimpah, namun sayangnya pemanfaatannya masih kurang.

Batubara merupakan salah satu sumber energi alternatif pengganti bahan bakar minyak (BBM). Cadangan batubara yang besar diketahui berada di wilayah Indonesia bagian barat. Cadangan tersebut berasal dari 11 cekungan, yang tersebar mulai dari Sumatera Utara, Jawa, hingga Kalimantan. Batubara di wilayah tersebut pada umumnya berumur tersier (20 sampai 5 juta tahun yang lalu), berupa sub-bituminous sampai lignit. Tetapi batubara kualitas rendah atau sub-bituminous masih jarang digunakan dibandingkan dengan batubara lignit.

Gasifier merupakan instrumen yang dapat mengkonversi berbagai bahan padat maupun cair seperti misalnya biomassa menjadi bahan bakar gas. Gasifier merupakan reaktor dimana berbagai proses kimia dan fisika yang kompelks dapat terjadi, seperti pengeringan, pemanasan, pirolisis, oksidasi parsial, dan reduksi. Melalui gasifikasi, bahan padat karbonat dipecah menjadi bahan-bahan dasar seperti $\mathrm{CO}, \mathrm{H}_{2}, \mathrm{CO}_{2}, \mathrm{H}_{2} \mathrm{O}$ dan $\mathrm{CH}_{4}$. Gas-gas yang dihasilkan selanjutnya dapat digunakan secara langsung untuk proses pembakaran maupun disimpan dalam tabung gas. Gas hasil dari proses gasifikasi disebut biogas, produser gas atau syngas (Vidian, 2008).

Pada proses gasifikasi dapat ditambahkan katalis guna mempercepat reaksi kimia. Efek dari penambahan katalis dapat mengurangi kebutuhan pereaksian sehingga prosesnya dapat terjadi pada temperatur rendah. Bentonit yang merupakan katalis yang berasal dari alam dapat di gunakan menjadi katalisator, hal ini pernah di uji oleh Dou, (2016).

Dikarenakan melimpahnya serbuk kayu galam dan batubara kualitas rendah, serta masih kurangnya pemanfaatanya, maka peneliti tertarik untuk meneliti bagaimana hasil syngas yang terjadi pada proses gasifikasi updraft limbah kayu galam dan batubara yang dipengaruhi oleh penambahan katalis bentonit.

\section{METODE PENELITIAN Objek Penelitian}

Dalam penelitian ini yang menjadi objek penelitian adalah limbah kayu galam dan batubara kualitas rendah berkatalis bentonit yang digasifikasi untuk mendapatkan produksi gas mampu bakar.

\section{Variabel Penelitian}

Variabel yang digunakan dalam penelitian ini adalah sebagai berikut :

1. Variabel bebas

Variabel bebas yang di ambil dalam penelitian ini adalah memvariasikan penambahan katalis dengan persentasi $50 \%$, 30\% dan $10 \%$ dari berat serbuk kayu galam dan batubara.

\section{Variabel terkontrol}

Variabel terkontrol dalam penelitian ini adalah berat total percampuran serbuk kayu galam dan batubara adalah 200 gram dan pencampuran bentonit dengan presentasi dari berat total pencampuran serbuk kayu dan batubara dengan lama waktu gasifikasi 120 menit dan suhu maksimal $500^{\circ} \mathrm{C}$. 
3. Variabel terikat

Variabel terikat dalam penelitian ini adalah data-data hasil dari proses gasifikasi yaitu volume gas.

\section{Alat dan Bahan Penelitian}

Adapun alat yang digunakan dalam penelitian ini adalah sebagai berikut :

1. Instalasi alat gasifikasi updraft (tungku biomassa)

Instalasi alat gasifikasi adalah instalasi alat-alat yang digunakan untuk melakukan seluruh proses gasifikasi mulai dari proses awal pemasukan campuran serbuk kayu galam, batubara dan bentonit hingga menjadi syngas. Instalasi alat gasifikasi dalam penelitian ini adalah sebagai berikut.

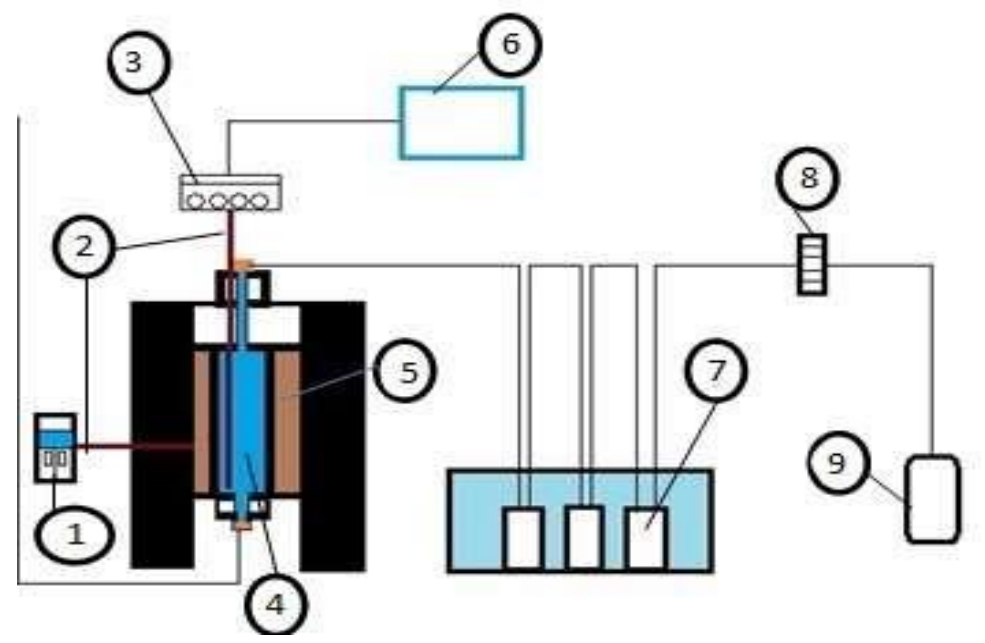

Gambar 1. Instalasi Alat Gasifikasi

Keterangan :
a. Thermocontroler
f. Laptop
b. Thermocouple
g. Elemeyer
c. Data Logger
h. Flowmeter
d. Tungku atau Furnace
i. Urine Bag
e. Heater

\section{Alat pendukung}

Alat pendukung adalah alat yang digunakan untuk sebelum dan sesudah proses gasifier. Alat pendukung yang digunakan dalam penelitian ini adalah sebagai berikut:
a. Oven
b. Stopwatch
c. Timbangan Elektrik
d. Alat penumbuk
e. Alat mesh atau ayakan

3. Bahan yang digunakan dalam penelitian ini adalah sebagai berikut:

a. Serbuk Kayu Galam (skg)

b. Batubara (bb)

c. Bentonit (bento) sebagai katalisnya, dan dengan variasi bahan dalam tabel 1,2 dan 3. 
Tabel 1. Komposisi campuran dari massa total $300 \mathrm{~g}$

\begin{tabular}{|l|c|c|c|}
\hline No & Serbuk kayu galam(g) & Batubara(g) & Bentonit (\%) dari massa bahan \\
\hline 1 & 200 & 0 & 50 \\
\hline 2 & 180 & 20 & 50 \\
\hline 3 & 140 & 60 & 50 \\
\hline 4 & 100 & 100 & 50 \\
\hline
\end{tabular}

Tabel 2. Komposisi campuran dari massa total $260 \mathrm{~g}$

\begin{tabular}{|l|c|c|c|}
\hline No & Serbuk kayu galam(g) & Batubara(g) & Bentonit (\%) dari massa bahan \\
\hline 1 & 200 & 0 & 30 \\
\hline 2 & 180 & 20 & 30 \\
\hline 3 & 140 & 60 & 30 \\
\hline 4 & 100 & 100 & 30 \\
\hline
\end{tabular}

Tabel 3. Komposisi campuran dari massa total $220 \mathrm{~g}$

\begin{tabular}{|l|c|c|c|}
\hline No & Serbuk kayu galam(g) & Batubara(g) & Bentonit (\%) dari massa bahan \\
\hline 1 & 200 & 0 & 10 \\
\hline 2 & 180 & 20 & 10 \\
\hline 3 & 140 & 60 & 10 \\
\hline 4 & 100 & 100 & 10 \\
\hline
\end{tabular}

\section{Proses Pengumpulan Data}

Ada beberapa tahapan dalam proses pengumpulan data, antara lain adalah sebagai berikut.

1. Proses persiapan bahan

Sebelum melakukan gasifikasi, serbuk kayu galam dan batubara harus dimasukkan ke dalam oven dengan temperatur $100^{\circ} \mathrm{C}$ dalam waktu 60 menit untuk menghilangkan kadar airnya. Setelah itu serbuk kayu galam di mesh agar terpisah dari kotoran dan serat kulit galam yang masih tercampur, untuk batubara di mesh menggunakan mesh $10(2 \mathrm{~mm})$ agar semua ukuran batubaranya merata. Sedangkan bentonit diaktifasi terlebih dahulu dengan cara dimasukkan ke dalam oven dengan suhu $300^{\circ} \mathrm{C}$.

2. Proses gasifikasi

a. Mempersiapkan alat gasifikasi. Dalam persiapan ini kita harus mengecek semua peralatan yang digunakan apakah semua peralatan bekerja dengan normal atau tidak.

b. Penimbangan. Sebelum dimasukan ke dalam tungku biomassa, serbuk kayu galam batubara dan bentonit ditimbang terlebih dahulu sesuai dengan persentasi variasi yang sudah ditentukan.

c. Memasukan bahan kedalam tungku, serbuk kayu galam, batubara dan bentonit yang sudah ditimbang dimasukkan ke dalam tungku biomassa per variasi lalu tutup rapat tungku.

d. Proses gasifikasi. Setelah bahan dimasukkan ke dalam tungku dan instalasi gasifier terpasang dengan sempurna, hidupkan saklar pada thermocouple, atur temperatur sesuai dengan yang diinginkan dan tekan tombol start pada aplikasi data loger.

e. Proses pengambilan data. Selama proses gasifikasi berjalan catat temperatur biomassa setiap lima menit dan catat waktu setiap 
kenaikan $50 \mathrm{~cm}$ pada flowmeter. Lakukan proses ini selama 120 menit dan jaga instalasi agar tidak terjadi kebocoran gas.

\section{Diagram Alur Penelitian}

Adapun diagram alur penelitian dapat dilihat pada Gambar 2.

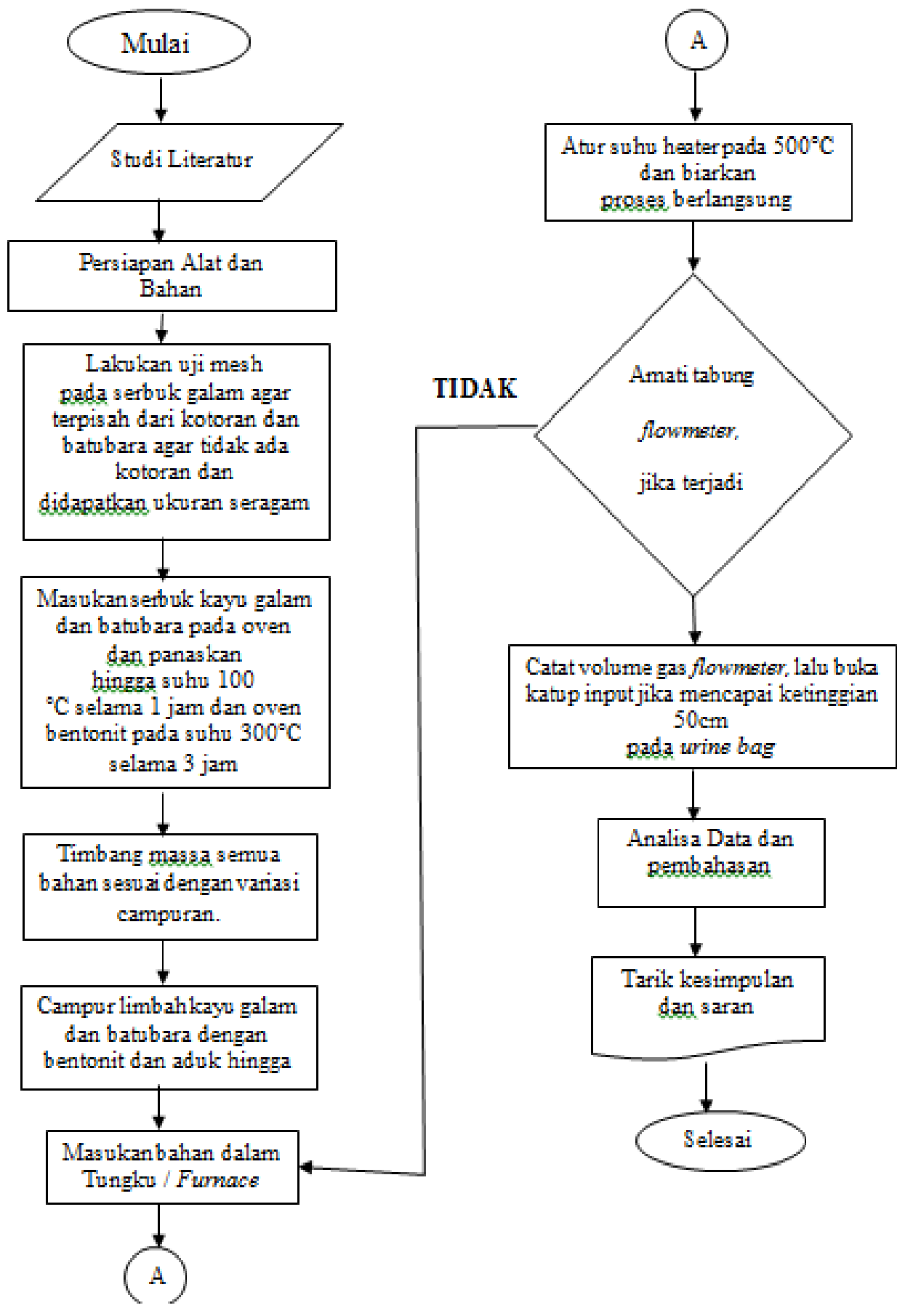

Gambar 2. Diagram Alur Penelitian 


\section{HASIL DAN PEMBAHASAN}

Data hasil penelitian yang di ambil berupa data volume syngas. Data hasil penelitian ini disajikan dalam bentuk tabel dan grafik.

Tabel 4. data hasil penelitian dari campuran $50 \%$ bentonit dari massa bahan

\begin{tabular}{|l|c|c|c|c|}
\hline \multirow{2}{*}{ No } & \multicolumn{2}{|c|}{ Bahan dengan massa 200g } & Volume gas & Volume gas (L/g) dari \\
& $\begin{array}{c}\text { Serbuk kayu } \\
\text { galam (g) }\end{array}$ & $\begin{array}{c}\text { Batubara } \\
\text { (g) }\end{array}$ & $(\mathbf{L})$ & $\begin{array}{c}\text { Vossa total 300g } \\
\text { mass }\end{array}$ \\
\hline 1 & 200 & 0 & 40,92 & 0,136 \\
\hline 2 & 180 & 20 & 34,73 & 0,115 \\
\hline 3 & 140 & 60 & 31,25 & 0,104 \\
\hline 4 & 100 & 100 & 30,53 & 0,101 \\
\hline
\end{tabular}

Tabel 5. data hasil penelitian dari campuran $30 \%$ bentonit dari massa bahan

\begin{tabular}{|c|c|c|c|c|}
\hline \multirow{2}{*}{ No } & \multicolumn{2}{|c|}{ Bahan dengan massa 200g } & Volume gas & $\begin{array}{c}\text { Volume gas (L/g) dari } \\
\text { massa total } \mathbf{2 6 0 g}\end{array}$ \\
\cline { 2 - 4 } & $\begin{array}{c}\text { Serbuk kayu } \\
\text { galam } \mathbf{( g )}\end{array}$ & $\begin{array}{c}\text { Batubara } \\
(\mathbf{g})\end{array}$ & $(\mathrm{L})$ & 0,148 \\
\hline 1 & 200 & 0 & 38,67 & 0,130 \\
\hline 3 & 180 & 20 & 33,89 & 0,115 \\
\hline 4 & 140 & 60 & 30,09 & 0,111 \\
\hline
\end{tabular}

Tabel 6. data hasil penelitian dari campuran $10 \%$ bentonit dari massa bahan

\begin{tabular}{|l|c|c|c|c|}
\hline \multirow{2}{*}{ No } & \multicolumn{2}{|c|}{ Bahan dengan massa 200g } & Volume gas & $\begin{array}{c}\text { Volume gas (L/g) dari } \\
\text { massa total 220g }\end{array}$ \\
\cline { 2 - 4 } & $\begin{array}{c}\text { Serbuk kayu } \\
\text { galam (g) }\end{array}$ & $\begin{array}{c}\text { Batubara } \\
(\mathbf{g})\end{array}$ & $(\mathbf{L})$ & 0,172 \\
\hline 1 & 200 & 0 & 37,88 & 0,149 \\
\hline 2 & 180 & 20 & 32,86 & 0,133 \\
\hline 3 & 140 & 60 & 29,38 & 0,122 \\
\hline 4 & 100 & 100 & 27,02 & \\
\hline
\end{tabular}

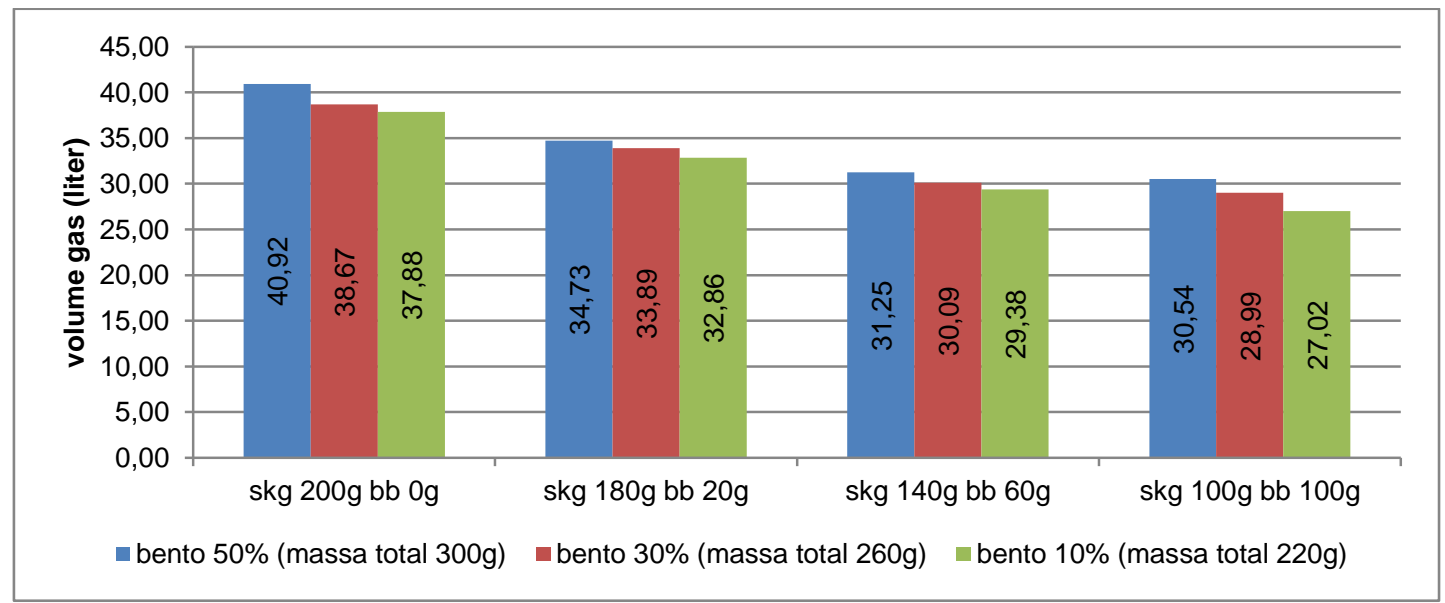

Gambar 3. Grafik perbandingan volume syngas dari persentase bentonit 50\%, $30 \%$, dan $10 \%$

Pada Gambar 3 dapat dilihat perbandingan volume syngas yang paling banyak adalah pada persentasi bentonit $50 \%$ dan yang paling sedikit adalah pada persentasi bentonit $10 \%$. 


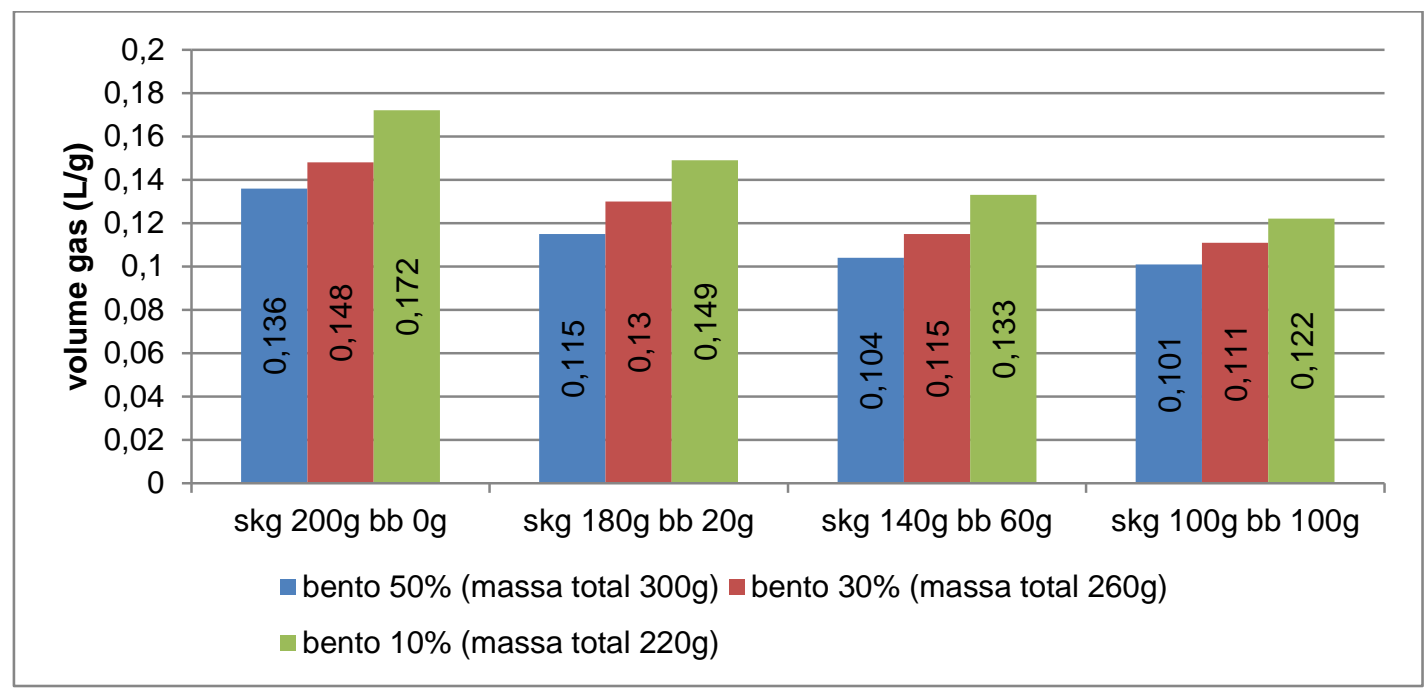

Gambar 4. Grafik perbandingan volume syngas per gram dari persentase bentonit $50 \%, 30 \%$, dan $10 \%$

Jika dilihat pada Gambar 4 volume syngas yang dihasilkan per gram nya, bentonit dengan persentase $10 \%$ (massa total $220 \mathrm{~g}$ ) lah yang menghasilkan gas yang paling banyak, sedangkan bentonit dengan persentasi $50 \%$ (massa total $300 \mathrm{~g}$ ) menghasilkan gas yang paling sedikit.

Pembahasan ini membahas tentang volume syngas pada proses gasifikasi updraft variasi campuran bahan serbuk kayu galam dan batubara dengan pengaruh bentonit.

1. Analisis volume syngas terhadap variasi campuran serbuk kayu galam dan

batubara

Berdasarkan grafik hasil di atas dapat dilihat bahwa semakin banyak persentasi serbuk kayu galam menghasilkan lebih banyak syngas dibandingkan dengan yang menggunakan persentasi batubara lebih banyak. Hal ini dikarenakan densitas batubara kualitas rendah susah terbakar di suhu $500^{\circ} \mathrm{C}$ dibanding dengan serbuk kayu galam.

2. Analisis volume syngas terhadap pengaruh pencampuran bentonit

Berdasarkan grafik hasil di atas penambahan katalis bentonit di setiap variasi dengan persentasi $50 \%, 30 \%$ dan $10 \%$ dari massa bahan. Pada percobaan menunjukan volume gas yang dihasilkan dari penambahan bentonit dengan persentasi yang lebih banyak menghasilkan volume gas lebih besar dibandingkan dengan penambahan bentonit yang lebih sedikit.

Hal ini sesuai dengan konsep catalytic cracking. Catalytic cracking pada percobaan kali ini didapatkan dari penambahan bentonit dimana dengan penambahan bentonit gas yang dihasilkan menjadi lebih banyak (A'yan, Dkk 2018).

Namun jika volume syngas dibagi dengan massa total serbuk kayu galam, batubara dan bentonit volume syngas yang paling banyak adalah variasi dengan massa total $220 \mathrm{~g}$ (penambahan $10 \%$ bentonit dari massa bahan) dibanding dengan variasi dengan massa total $260 \mathrm{~g}$ (penambahan bentonit $30 \%$ bentonit dari massa bahan), dan yang paling sedikit ialah variasi dengan massa total $300 \mathrm{~g}$ (penambahan $50 \%$ bentonit dari massa bahan). 


\section{KESIMPULAN}

Berdasarkan hasil penelitian mengenai pengaruh variasi campuran bahan serbuk kayu galam dan batubara dengan pengaruh bentonit terhadap hasil gasifikasi updraft, dapat diambil kesimpulan sebagai berikut :

1. Variasi yang menggunakan persentasi serbuk kayu galam lebih banyak menghasilkan syngas yang lebih banyak dibanding dengan variasi lain yang menggunakan persentasi batubara lebih banyak.

2. Penggunaan bentonit dapat mempercepat reaksi dikarenakan bentonit memiliki kandungan $\mathrm{Al}_{2} \mathrm{O}_{3}$ yang memiliki konduktivitas panas yang baik, sehingga laju pemanasan pada tungku lebih cepat. Dikarenakan laju pemanasan lebih cepat membuat volume syngas yang di hasilkan lebih banyak selama 120 menit. namun jika volume syngas di bagi dengan massa total bahan dan katalis maka syngas yang paling banyak adalah variasi dengan massa total $220 \mathrm{~g}$ atau yang menggunakan katalis paling sedikit.

\section{DAFTAR PUSTAKA}

A'Yan Sabitah, Nurkholis Hamidi, Slamet Wahyudi. "Gasifikasi Biomassa Limbah Sawit Dengan Penambahan Katalis Bentonit”. Program Studi Teknik Mesin, Universitas Brawijaya, Malang, Indonesia.

Dou. et al. 2016. "In situ upgrading of pyrolysis biofuels by bentonite clay with simultaneous production of heterogeneous adsorbents for water treatment". Department of Mechanical Engineering, Boston University.

Fajri Vidian, 2008. "Gasifikasi Tempurung Kelapa Menggunakan Updraft Gasifier pada Beberapa Variasi Laju Alir Udara Pembakaran," Jurusan Teknik Mesin, Fakultas Teknik, Universitas Sriwijaya, Palembang.

Maharjoeno,E.2005. "Energi Alternatif Penggenti BBM: Potensi Limbah Biomassa Sawit Sebagai Sebagai Sumber Energi Terbarukan". Lembaga Riset Perkebunan Indonesia. Jakarta.

Rachmanady, D., Lazuardi, D. \& Agustinus, P.T. 2004. "Teknik Persemaian dan Informasi Benih Gelam". Yogyakarta: Pusat Penelitian dan Pengembangan Bioteknologi dan Pemuliaan Tanaman Hutan. 